\title{
Pulmonary artery sarcoma with angiosarcoma phenotype mimicking pleomorphic malignant fibrous histiocytoma: a case report
}

\author{
Olga L Bohn ${ }^{1,5^{*}}$, Eric Acosta-Ponce de León², Oscar Lezama ${ }^{3}$, Nina P Rios-Luna ${ }^{1}$, Sergio Sánchez-Sosa ${ }^{1}$ \\ and Antonio Llombart-Bosch ${ }^{4}$
}

\begin{abstract}
Primary sarcomas of the major blood vessels can be classified based on location in relationship to the wall or by histologic type. Angiosarcomas are malignant neoplasms that arise from the endothelial lining of the blood vessels; those arising in the intimal compartment of pulmonary artery are rare. We report a case of pulmonary artery angiosarcoma in a 36-year old female with pulmonary masses. The patient had no other primary malignant neoplasm, thus excluding a metastatic lesion. Gross examination revealed a thickened right pulmonary artery and a necrotic and hemorrhagic tumor, filling and occluding the vascular lumen. The mass extended distally, within the pulmonary vasculature of the right lung. Microscopically, an intravascular undifferentiated tumor was identified. The tumor cells showed expression for vascular markers VEGFR, VEGFR3, PDGFRa, FGF, Ulex europaeus, FVIII, FLI-1, CD31 and CD34; p53 was overexpressed and Ki67 proliferative rate was increased. Intravascular angiosarcomas are aggressive neoplasms, often associated with poor outcome.
\end{abstract}

Virtual slide: The virtual slide(s) for this article can be found here: http://www.diagnosticpathology.diagnomx.eu/vs/ 2315906377648045.

Keywords: Pulmonary artery, Sarcoma, Angiosarcoma, Immunohistochemistry

\section{Background}

Primary sarcomas of the major blood vessels can be classified based on location in relationship to the wall (mural or intraluminal (also known as "intimal") or by histologic type. Angiosarcomas are malignant tumors that arise from the endothelial lining of the blood vessels [1]. Pulmonary artery sarcomas (PAS) include two types: intimal sarcomas, presenting as intraluminal growing excrescences, and mural sarcomas, involving the pulmonary artery wall. PAS are rare tumors, with unknown and probably, underestimated incidence, which may show myofibroblastic, leiomyosarcomatous, osteosarcomatous, rhabdomyosarcomatous or angiosarcomatous differentiation [2]. Angiosarcoma of the pulmonary artery is a distinctive tumor and few cases have been reported to the date $[2,3]$.

\footnotetext{
* Correspondence: olga.bohn@gmail.com

'Department of Pathology, Christus Mugerza UPAEP University Hospital, Puebla 72000, Mexico

${ }^{5}$ Current affiliation: Memorial Sloan-Kettering Cancer Center, New York, NY, USA

Full list of author information is available at the end of the article
}

\section{Case presentation}

A 36-year-old female presented to the clinic with a 3-month history of non-productive cough and weight loss. Her past medical history was unremarkable. Chest X-rays and a computed tomography $(\mathrm{CT})$ scan showed two right perihilar lung masses, each measuring 3.5 and $2.5 \mathrm{~cm}$ in greater diameter, adjacent to the main right pulmonary artery (Figure 1). No extrapulmonary masses were identified by PET scan and CT; therefore, metastatic disease was excluded. A bronchoscopy was performed and transbronchial biopsies were taken but were non diagnostic. She had a thoracoscopic exploration and an open-lung biopsy. A pathology report showed a malignant fibrous histiocytoma (MFH) of the lung. A right pneumonectomy was performed and she required 2 days in the ICU; pulmonary artery hypertension and tachycardia developed, which resolved with digoxin and diltiazem.

\section{Pathological findings}

The specimen consisted of a total right lung, weighing 994 grams and measuring $35 \times 11 \times 7 \mathrm{~cm}$. On the

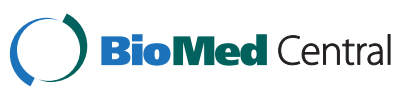




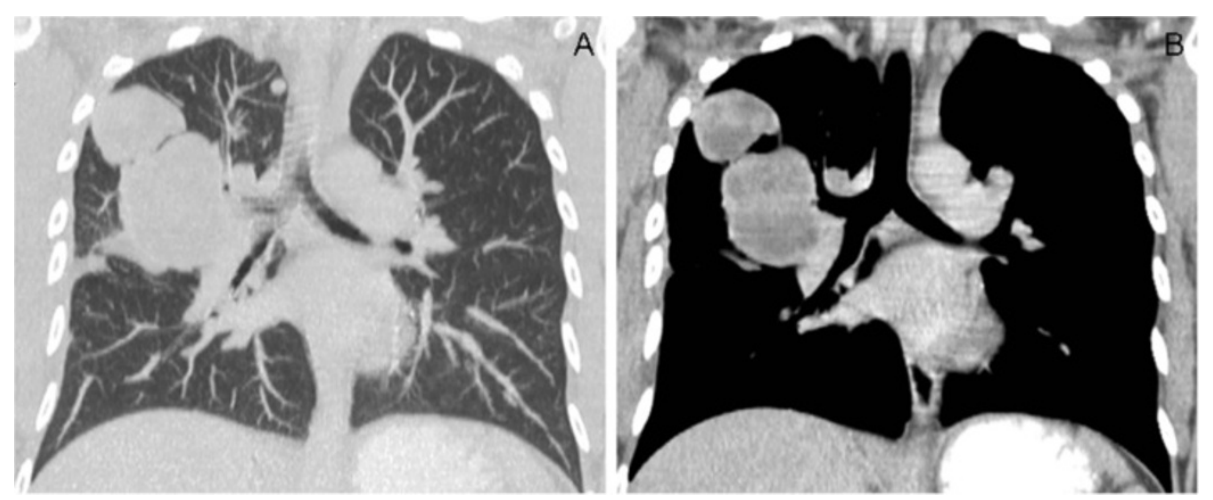

Figure 1 Pulmonary artery angiosarcoma. A and B. CT-chest shows two circumscribed pulmonary masses.

anterior aspect of the right upper lobe, two masses that abut pleural surfaces were identified. Cut sections showed a right pulmonary artery thickening and a necrotic and hemorrhagic tumor, filling and near occluding the vascular lumen (Figure 2). The mass extended distally, within the pulmonary vasculature of the right lung. The smaller arterial branches were thickened. In addition, the lung parenchyma showed two lobulated and circumscribed yellow-tan masses with necrosis, hemorrhage and myxoid appearance, measuring $3.5 \times$ $3.2 \times 3 \mathrm{~cm}$ and $2.5 \times 2 \times 2 \mathrm{~cm}$. The bronchial and vascular margins of resection were free of tumor.

Microscopic examination showed an intravascular undifferentiated tumor composed of loosely cohesive large, pleomorphic spindle and epithelioid cells with prominent nucleoli, admixed with multinucleated giant cells (Figure 3). Numerous mitotic figures were seen. Interestingly, the pleomorphic tumor cells were found arising from the intima of the vessels, extending and occupying the vascular lumen. Medium sized vessels showed intraluminal tumor. Masson's trichrome was useful to identify vessels components and the origin of tumor cells (not shown). The lung parenchyma also revealed a tumor similar that presented in pulmonary vessel, with solid, myxoid and hemangiopericytoid growth patterns. The original biopsy slides were reviewed, and the findings were identical to those identified within the vascular spaces and lung parenchyma. The original biopsy diagnosis was MFH pleomorphic variant.

A broad panel of immunohistochemical markers was used as shown in Table 1. The tumor cells showed strong positivity for Vimentin, FGF, PDGFRa, Factor VIII, Ulex europaeus, FLI1, CD31 and CD34; VE-cadherin, VEFGR and VEGFR3 were focal positive in epithelioid tumor cells; there was p53 overexpression (25\%) and Ki67 proliferative rate ranged from 10 to $40 \%$ (Figure 4). Tumor cells lacked expression for AE1AE3, EMA, CK 8/18, HMB45, Melan A, desmin, h-Caldesmon, SMA and S100.

Based on clinical, radiological and histopathological findings, the tumor was diagnosed as angiosarcoma arising on the pulmonary artery.
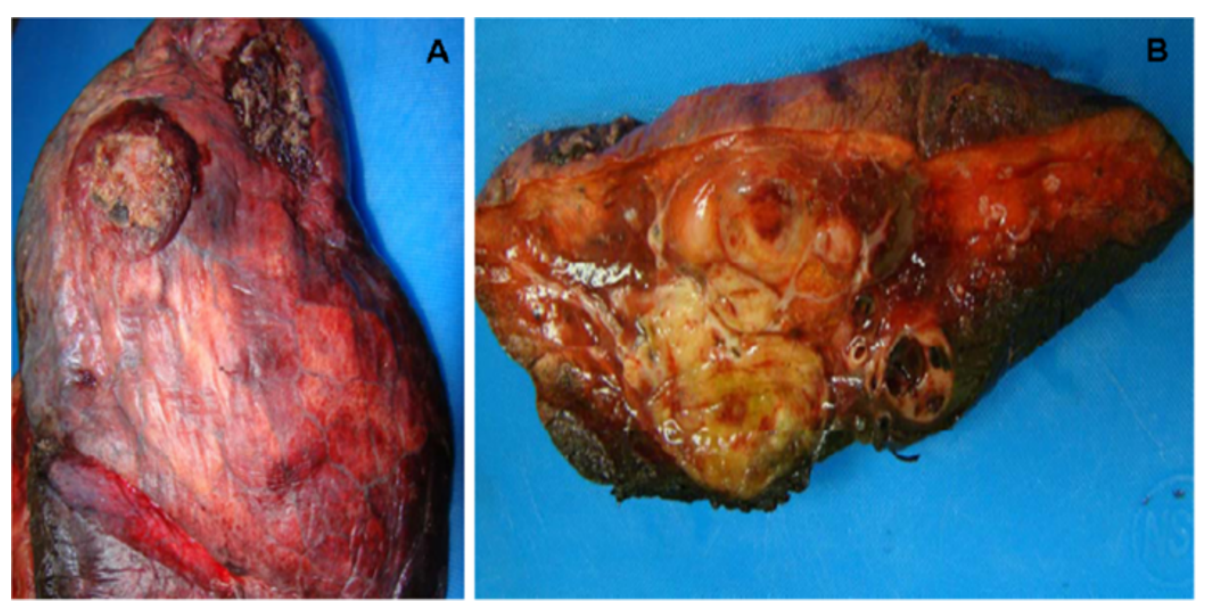

Figure 2 Pulmonary artery angiosarcoma. A. Tumor abutting the pleural surface. B. Right pneumonectomy showing intraparenchymal masses and near total right pulmonary occlusion. 


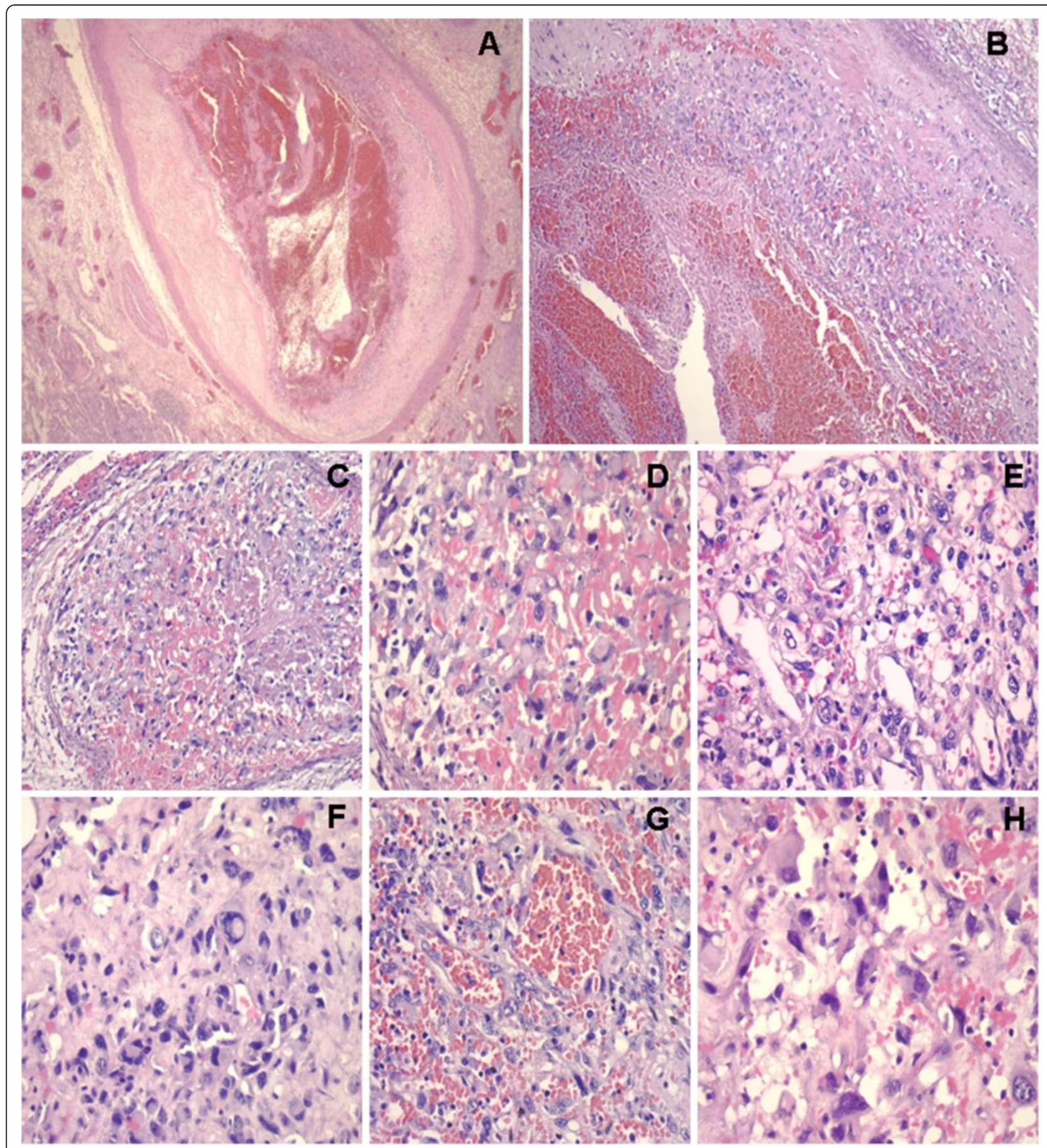

Figure 3 Pulmonary artery angiosarcoma. A, B. Endovascular tumor with intimal component (HE 40X, 10X). C, D. Intravascular angioblastic proliferation (HE 200X, 400X). E. Malignant tumor cells with vacuoles (HE 400X). F. Large epithelioid malignant tumor cells (HE 400X).

G. Angioblasts within malignant vascular neoformation (HE 200X). H. Atypical endothelial proliferation (HE 400X).

\section{Clinical follow-up}

The patient received four cycles of ifosfamide-based chemotherapy with tolerable toxicity. Eighteen months after diagnosis an extensive radiological examination showed no other primary neoplasm or metastatic lesion. The patient was disease free 18 months and then the tumor recurred (additional biopsies were taken showing similar histopathological findings). She developed metastatic disease to liver and contralateral lung and died 29 months after the recurrence. No autopsy was performed. Primary sarcomas arising from major blood vessels (aorta, pulmonary artery, inferior vena cava) are 
Table 1 List of antibodies

\begin{tabular}{|c|c|c|c|}
\hline ANTIBODY & CLONE & SOURCE & DILUTION \\
\hline VIMENTIN & Monoclonal mouse V9 & Novocastra & $1: 300$ \\
\hline CD31 & Monoclonal mouse anti-h JC70A & DAKO & $1: 100$ \\
\hline CD34 & Monoclonal mouse QBEnd/10 & Novocastra & 1:100 \\
\hline VE-CADHERIN & Goat polyclonal & Santa cruz Biotechnology & 1:100 \\
\hline VEGF & Mouse monoclonal VG1 & Neomarkers & 1:100 \\
\hline VEGFR3 & Rabbit polyclonal & Santa cruz Biotechnology & $1: 400$ \\
\hline PDGFRa & Rabbit polyclonal & Santa cruz Biotechnology & 1:100 \\
\hline FGF-2 & Rabbit polyclonal & Santa cruz Biotechnology & $1: 200$ \\
\hline Factor VIII & Rabbit polyclonal & DAKO & $1: 200$ \\
\hline ULEX EUROPAEUS-I LECTIN & Rabbit polyclonal & Sigma & $1: 500$ \\
\hline FLI-1 & Monoclonal mouse MRQ1 & Cell Marque & 1:100 \\
\hline EMA & Monoclonal mouse E29 & DAKO & 1:100 \\
\hline CK 8/18 & Monoclonal mouse 5D3 & Novocastra & $1: 50$ \\
\hline CK AE1-AE3 & Monoclonal mouse AE1-AE3 & DAKO & 1:100 \\
\hline$S 100$ & Rabbit polyclonal & DAKO & $1: 600$ \\
\hline HMB45 & HMB45 & DAKO & 1:100 \\
\hline Melan A & A103 & DAKO & $1: 50$ \\
\hline Desmin & DE-R11 & DAKO & 1:100 \\
\hline h-Caldesmon & Monoclonal mouse h-CD & DAKO & $1: 50$ \\
\hline Ki67 & Monoclonal mouse MIB-1 & DAKO & $1: 200$ \\
\hline P53 & Monoclonal mouse DO-7 & Novocastra & $1: 50$ \\
\hline
\end{tabular}

VE indicates vascular endothelial; VEGF, vascular endothelial growth factor; PDGFRa, platelet-derived growth factor receptor alpha; FGF, fibroblast growth factor; EMA, epithelial membrane antigen; CK, cytokeratin.

exceedingly rare [4-8], and some of the cases presented in the literature have been autopsy reports $[5,9,10]$. Most patients are adults, however, a few cases have been found in children [11]. Burke et al. [5] found that intimal sarcomas affect males more frequently than females and arise predominatly in the right pulmonary vessels, with intraluminal involvement rather than intraparenchymal infiltration.

Clinically, primary sarcomas of the major blood vessels, are usually associated to embolic phenomena $[6,12,13]$; therefore, their true incidence is probably underestimated because of misdiagnosis with thromboembolism, especially when located at aorta [11]. The radiographic distinction of pulmonary thromboembolic disease and pulmonary artery sarcoma (PAS) is challenging, because both conditions appear as intraluminal filling defects in the pulmonary artery system on contrast-enhanced CT scans $[14,15]$. Some authors have reported that the diagnosis may be suspected by magnetic resonance imaging (MRI) $[4,6]$ and positron emission tomography (PET) [15]. However, findings that favor a diagnosis of a PAS include the heterogeneous soft tissue density and the enhancement of the gadolinium contrast $[11,16]$. Therefore, PAS should always be considered as a possibility, as a misdiagnosis with thromboembolic disease will result in delaying appropriate therapy and increased morbi-mortality [15,17].

Grossly, a careful examination of the specimen, the pulmonary vasculature and its branches is essential to achieve the correct diagnosis. PAS may spread and grow as intraluminal masses along the endothelium and an organizing thromboemboli needs to be ruled out [18]. In addition, direct lung parenchyma involvement is a common event, as direct extension through the pulmonary vasculature can occur due to the prominent intravascular growth along the arterial intima. On the other hand, mural sarcomas with a solid growth can also be confused with other entities including metastatic extension from primary malignancies of the lung or tumors from the mediastinum, such as lymphoma and sarcomas [19]. In our case, an extensive work-up that included clinical and radiological evaluation was a key determinant for the appropriate conclusion of the case.

Pulmonary artery sarcomas of the lung are malignant tumors of indeterminate cause, usually presenting heterogenous histology that most likely reflect a pluripotential or mesenchymal cell origin [20]. Some examples that have been reviewed in the literature represent undifferentiated sarcomas that may display a myofibroblastic 


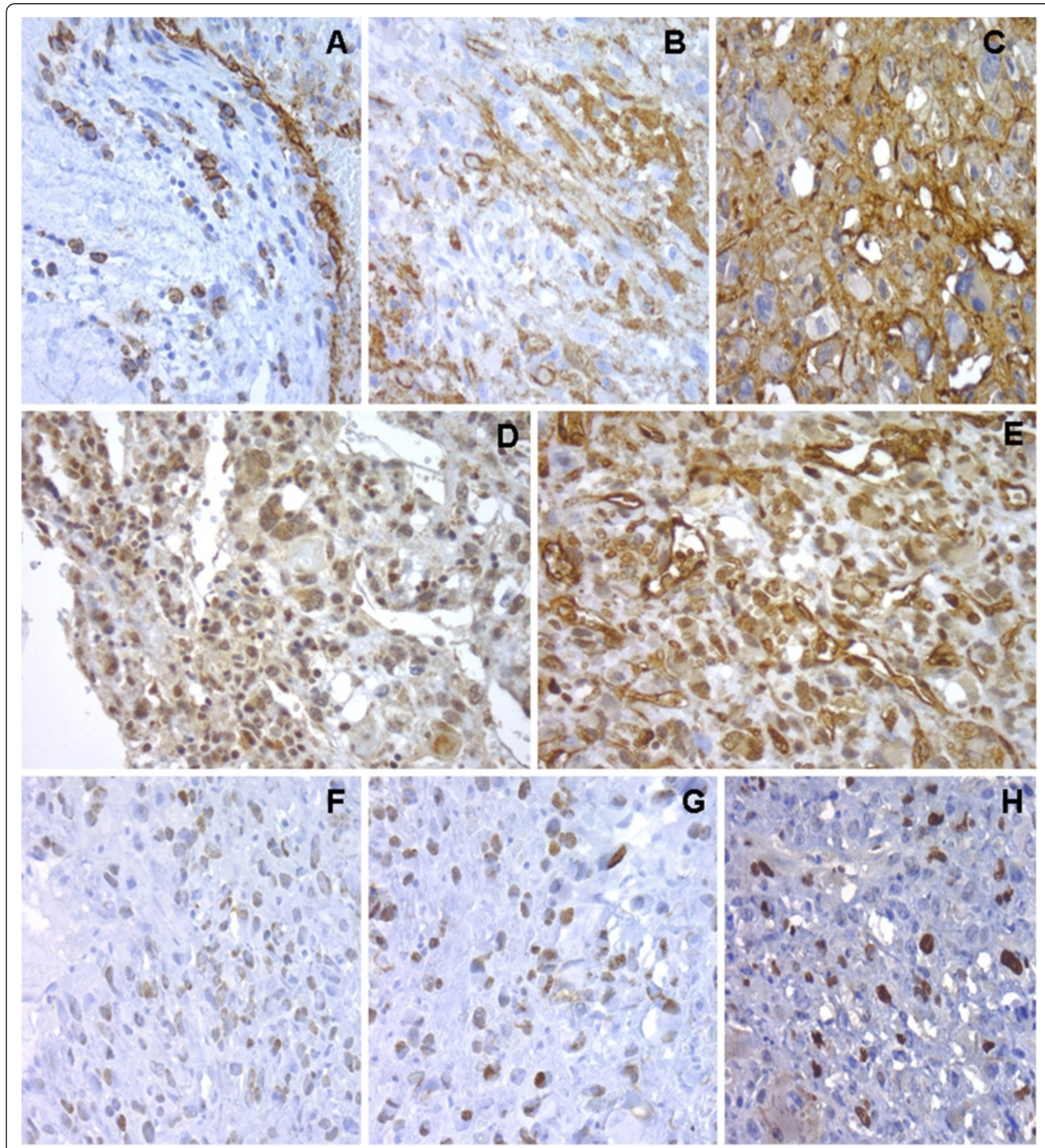

Figure 4 Pulmonary artery angiosarcoma. A. CD31 expression in tumor cells. B. CD34 highlights tumor cells. C. Strong positivity for Factor VIII. D. FLI-1 shows nuclear expression. E. Ulex europaeus positive staining. F. FGF expression. G. Ki67 nuclear staining. H. p53 nuclear staining.

or leiomyosarcomatous component [5,18]; nevertheless, osteosarcomatous, chondrosarcomatous, rhabdomyosarcomatous, liposarcomatous and angiosarcomatous elements have also been described [5,6,8-10,21-23]. The present case displays an undifferentiated sarcoma that mimics pleomorphic malignant fibrous histiocytoma; however, the tumor expresses the majority of vascularspecific markers. It is important to highlight that the final diagnosis could not have been achieved without a high level of suspicion. Interestingly, one of the most significant features helpful for identification of angiosarcoma was the intimal origin of the tumor. Furthermore, 
undifferentiated tumors as primary pulmonary angiosarcomas have been confused with malignant neoplasms (primary or metastatic malignancies) with dedifferentiated component, such as carcinomas, sarcomas and lymphomas [24-27]. Differential diagnoses in this specific case include high grade sarcomas with leiomyosarcomatous, fibro or myofibroblastic differentiation. For that reason, an appropriate and consecutive utilization of a broad panel of antibodies, and occasionally, electron microscopy (not used in this case) are often necessary to distinguish the origin $[8,13,28]$. We found in this case, that co-expression of endothelial markers such as VEGF, PDGFR, Ulex europaeus, FLI1, CD31 and CD34 is useful in classifying the neoplasm, representing an unusual presentation of a true angiosarcoma similar to those observed in soft tissues.

Although in this case it was not possible to identify specific exposure, angiosarcomas have been reported associated to previous irradiation fields [29] or arteriovenous fistulas [30]. Comparative genomic hybridization (CGH) analysis of intimal pulmonary sarcomas have shown gains and amplifications in the 12q13-14 region, with other less consistent findings including losses on 3p, 3q, 4q, 9p, 11q, 13q, Xp, and Xq, gains on 7p, 17p, and 17q, and amplifications on 4q, 5p, 6p, and 11q [18]. Currently, no prognostic markers have been extensively studied; however, in one study, Gaumann et al. [31] found that osteopontin expression may contribute to metastasis due to its role in cell attachment and therefore to poor prognosis. In addition, Bode-Lesniewska et al. [18] reported that dysregulation of the cell cycle proteins in p53 pathway and overexpression of $\mathrm{mdm} 2$ might be implicated in the pathogenesis. At this point, further gene profiling studies, including a larger group of this specific type of vascular malignancy can be used to identify predictive and prognostic markers for intravascular angiosarcoma of the pulmonary vessels.

Overall, PAS are considered aggressive neoplasms, often associated to poor outcome irrespective of treatment $[9,10,32,33]$, and with no exception for pulmonary artery angiosarcomas. Only few patients have survived more than 12 months [5,34]; surgery and complete resection of the tumor provide local control. Adjuvant chemotherapy and radiotherapy have a controversial role in the management of this disease [5,33]. The role of chemotherapy is unclear, but a $50 \%$ response rate has been found to palliative chemotherapy with anthracyclines and ifosfamide in patients with advanced PAS $[11,35]$.

\section{Conclusion}

In summary, we report an unusual case of pulmonary artery sarcoma with angiosarcoma phenotype that mimics pleomorphic malignant fibrous histiocytoma. A high level of suspicion and identification of the intimal location of the tumor, in addition to the use of a broad panel of immunohistochemical markers were helpful for the identification of the vascular origin. A multidisciplinary clinical and radiological approach and an extensive work-up were key determinant for the appropriate conclusion of the case.

\section{Consent}

Written informed consent was obtained from the patient's family members for publication of this Case Report and any accompanying images. A copy of the written consent is available for review by the Editor-in Chief of this journal.

\section{Competing interests}

The authors declare that they have no competing interests.

\section{Authors' contributions}

$\mathrm{OB}, \mathrm{EA}, \mathrm{OL}, \mathrm{NR}$, SS and $\mathrm{AL}$ have been directly involved in diagnosis and interpretation of patient's diagnosis. $\mathrm{OB}, \mathrm{SS}$ and $\mathrm{AL}$ were responsible for the conception and design of the Case Report. All authors read and approved the final manuscript.

\section{Author details}

${ }^{1}$ Department of Pathology, Christus Mugerza UPAEP University Hospital, Puebla 72000, Mexico. ${ }^{2}$ Department of Surgical Oncology, Hospital Angeles, 5 Poniente 715, Puebla, Mexico. ${ }^{3}$ Department of Radiology, Hospital Angeles, Puebla, México. ${ }^{4}$ Department of Pathology, Valencia University, Valencia, Spain. ${ }^{5}$ Current affiliation: Memorial Sloan-Kettering Cancer Center, New York, NY, USA.

Received: 14 July 2012 Accepted: 31 October 2012

Published: 7 November 2012

\section{References}

1. Rosai J (Ed): Rosai and Ackerman's Surgical Pathology, 10th edition. Philadelphia: Mosby Elservier; 2011.

2. Huo L, Moran CA, Fuller GN, Gladish G, Suster S: Pulmonary artery sarcoma: a clinicopathologic and immunohistochemical study of 12 cases. Am J Clin Pathol 2006, 125:419-424.

3. Huo L, Lai S, Gladish G, Czerniak BA, Moran CA: Pulmonary artery angiosarcoma: a clinicopathologic and radiological correlation. Ann Diagn Pathol 2005, 9:209-214.

4. Seelig MH, Klingler PJ, Oldenburg WA, Blackshear JL: Angiosarcoma of the aorta: report of a case and review of the literature. J Vasc Surg 1998 28:732-737.

5. Burke AP, Virmani R: Sarcomas of the great vessels. A clinicopathologic study. Cancer 1993, 71:1761-1773.

6. Santonja C, Costa-Subias J, Martin-Hita AM, Dotor A: Intimal angiosarcoma of the aorta with tumour embolisation causing mesenteric ischaemia. Report of a case diagnosed using CD31 immunohistochemistry in an intestinal resection specimen. Virchows Arch 2001, 438:404-407.

7. Hottenrott G, Mentzel T, Peters A, Schroder A, Katenkamp D: Intravascular ("intimal") epithelioid angiosarcoma: clinicopathological and immunohistochemical analysis of three cases. Virchows Arch 1999, 435:473-478.

8. Miracco C, Laurini L, Santopietro R, De Santi MM, Sassi C, Neri E, Pepi F, Luzi P: Intimal-type primary sarcoma of the aorta. Report of a case with evidence of rhabdomyosarcomatous differentiation. Virchows Arch 1999, 435:62-66.

9. Nonomura A, Kurumaya H, Kono N, Nakanuma Y, Ohta G, Terahata S, Matsubara F, Matsuda T, Asaka T, Nishino T: Primary pulmonary artery sarcoma. Report of two autopsy cases studied by immunohistochemistry and electron microscopy, and review of 110 cases reported in the literature. Acta Pathol Jpn 1988, 38:883-896. 
10. Gaumann A, Tews DS, Mayer E, Dahm M, Petrow PK, Otto M, Kirkpatrick CJ Kriegsmann J: Expression of apoptosis-related proteins, p53, and DNA fragmentation in sarcomas of the pulmonary artery. Cancer 2001, 92:1237-1244

11. Chappell T, Creech CB, Parra D, Strauss A, Scholl F, Whitney G: Presentation of pulmonary artery intimal sarcoma in an infant with a history of neonatal valvular pulmonic stenosis. Ann Thorac Surg 2008, 85:1092-1094.

12. Nishida N, Yutani $C$, Ishibashi-Ueda H, Tsukamoto $Y$, Ikeda $Y$, Nakamura $Y$ Histopathological characterization of aortic intimal sarcoma with multiple tumor emboli. Pathol Int 2000, 50:923-927.

13. Goldblum JR, Rice TW: Epithelioid angiosarcoma of the pulmonary artery. Hum Pathol 1995, 26:1275-1277.

14. Scheffel H, Stolzmann P, Plass A, Weber A, Pretre R, Marincek B, Alkadhi H: Primary intimal pulmonary artery sarcoma: a diagnostic challenge. J Thorac Cardiovasc Surg 2008, 135:949-950.

15. Thurer RL, Thorsen A, Parker JA, Karp DD: FDG imaging of a pulmonary artery sarcoma. Ann Thorac Surg 2000, 70:1414-1415.

16. Yi ES: Tumors of the pulmonary vasculature. Cardiol Clin 2004, 22:431-440. vi-vii.

17. Scheidl S, Taghavi S, Reiter U, Troster N, Kovacs G, Rienmuller R, Lang S, Klepetko W, Olschewski H: Intimal sarcoma of the pulmonary valve. Ann Thorac Surg 2010, 89:e25-e27.

18. Bode-Lesniewska B, Zhao J, Speel EJ, Biraima AM, Turina M, Komminoth P, Heitz PU: Gains of 12q13-14 and overexpression of mdm2 are frequent findings in intimal sarcomas of the pulmonary artery. Virchows Arch 2001, 438:57-65.

19. Sebenik M, Ricci A Jr, DiPasquale B, Mody K, Pytel P, Jee KJ, Knuutila S, Scholes J: Undifferentiated intimal sarcoma of large systemic blood vessels: report of 14 cases with immunohistochemical profile and review of the literature. Am J Surg Pathol 2005, 29:1184-1193.

20. McGlennen RC, Manivel JC, Stanley SJ, Slater DL, Wick MR, Dehner LP: Pulmonary artery trunk sarcoma: a clinicopathologic, ultrastructural, and immunohistochemical study of four cases. Mod Pathol 1989, 2:486-494.

21. Johansson L, Carlen B: Sarcoma of the pulmonary artery: report of fou cases with electron microscopic and immunohistochemical examinations, and review of the literature. Virchows Arch 1994, 424:217-224.

22. Baker PB, Goodwin RA: Pulmonary artery sarcomas. A review and report of a case. Arch Pathol Lab Med 1985, 109:35-39.

23. Tavora F, Miettinen M, Fanburg-Smith J, Franks TJ, Burke A: Pulmonary artery sarcoma: a histologic and follow-up study with emphasis on a subset of low-grade myofibroblastic sarcomas with a good long-term follow-up. Am J Surg Pathol 2008, 32:1751-1761.

24. Hisaoka M, Tsuji S, Hashimoto H, Aoki T, Uriu K: Dedifferentiated liposarcoma with an inflammatory malignant fibrous histiocytoma-like component presenting a leukemoid reaction. Pathol Int 1997, 47:642-646.

25. Hollowood K, Holley MP, Fletcher CD: Plexiform fibrohistiocytic tumour clinicopathological, immunohistochemical and ultrastructural analysis in favour of a myofibroblastic lesion. Histopathology 1991, 19:503-513.

26. Kao YC, Chow JM, Wang KM, Fang CL, Chu JS, Chen CL: Primary pleural angiosarcoma as a mimicker of mesothelioma: a case report ${ }^{* *} \mathrm{VS}^{* *}$. Diagn Pathol 2011, 6:130.

27. Jinghong $X$, Lirong C: Pulmonary epithelioid hemangioendothelioma accompanied by bilateral multiple calcified nodules in lung. Diagn Pathol 2011, 6:21.

28. Emmert-Buck MR, Stay EJ, Tsokos M, Travis WD: Pleomorphic rhabdomyosarcoma arising in association with the right pulmonary artery. Arch Pathol Lab Med 1994, 118:1220-1222.

29. Davies JD, Rees GJ, Mera SL: Angiosarcoma in irradiated post-mastectomy chest wall. Histopathology 1983, 7:947-956.

30. Byers RJ, McMahon RF, Freemont AJ, Parrott NR, Newstead CG: Epithelioid angiosarcoma arising in an arteriovenous fistula. Histopathology 1992 21:87-89.

31. Gaumann A, Petrow P, Mentzel T, Mayer E, Dahm M, Otto M, Kirkpatrick CJ, Kriegsmann J: Osteopontin expression in primary sarcomas of the pulmonary artery. Virchows Arch 2001, 439:668-674.

32. Anderson MB, Kriett JM, Kapelanski DP, Tarazi R, Jamieson SW: Primary pulmonary artery sarcoma: a report of six cases. Ann Thorac Surg 1995, 59:1487-1490.

33. Gaumann A, Bode-Lesniewska B, Zimmermann DR, Fanburg-Smith JC, Kirkpatrick CJ, Hofstadter F, Woenckhaus M, Stoehr R, Obermann EC,
Dietmaier W, Hartmann A: Exploration of the APC/beta-catenin (WNT) pathway and a histologic classification system for pulmonary artery intimal sarcoma. A study of 18 cases. Virchows Arch 2008, 453:473-484

34. Mayer E, Kriegsmann J, Gaumann A, Kauczor HU, Dahm M, Hake U, Schmid FX, Oelert H: Surgical treatment of pulmonary artery sarcoma. J Thorac Cardiovasc Surg 2001, 121:77-82.

35. Manso L, Alvarez E, Quintela M, Cortes-Funes H, Hitt R: Primary pulmonary artery sarcoma: report of three cases and review of the literature. Clin Lung Cancer 2007, 8:277-281.

doi:10.1186/1746-1596-7-154

Cite this article as: Bohn et al:: Pulmonary artery sarcoma with angiosarcoma phenotype mimicking pleomorphic malignant fibrous histiocytoma: a case report. Diagnostic Pathology 2012 7:154

\section{Submit your next manuscript to BioMed Central and take full advantage of:}

- Convenient online submission

- Thorough peer review

- No space constraints or color figure charges

- Immediate publication on acceptance

- Inclusion in PubMed, CAS, Scopus and Google Scholar

- Research which is freely available for redistribution

Submit your manuscript at www.biomedcentral.com/submit
C Biomed Central 